\title{
Optimalisasi UKS dalam Penanganan Kegawatdaruratan Dasar di Sekolah melalui Pelatihan Kegawatdaruratan Dasar bagi PMR di SMP Bayt Al-Hikmah Kota Pasuruan
}

\author{
Marsaid $^{1}$
}

${ }^{1}$ Poltekkes Kemenkes Malang, Indonesia

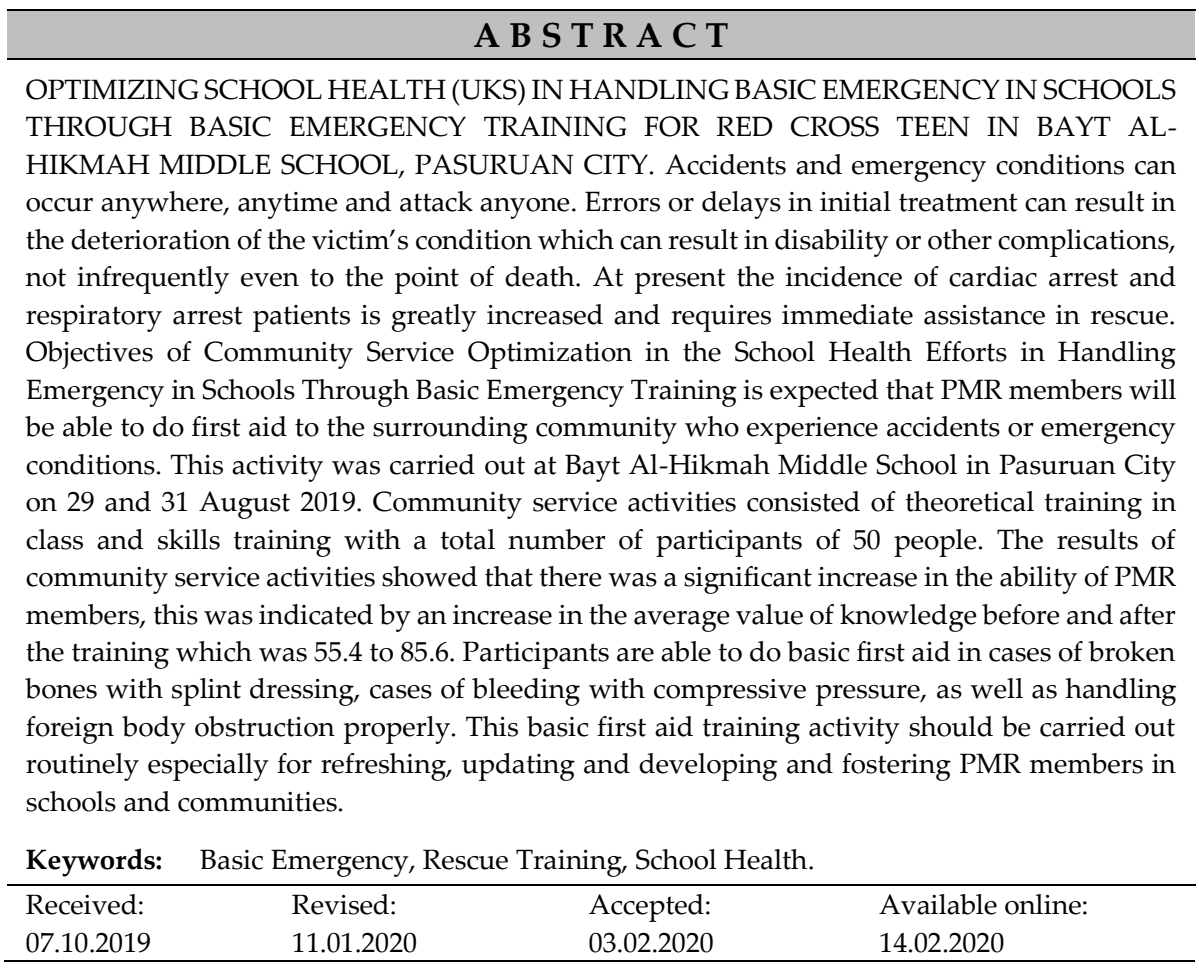

\section{Suggested citation:}

Marsaid. (2020). Optimalisasi UKS dalam penanganan kegawatdaruratan dasar di sekolah melalui pelatihan kegawatdaruratan dasar bagi PMR di SMP Bayt Al-Hikmah Kota Pasuruan. Jurnal Pengabdian Pada Masyarakat, 5(1), 117-124. https://doi.org/10.30653/002.202051.263

Open Access I URL: http://ppm.ejournal.id/index.php/pengabdian/article/view/263

\footnotetext{
${ }^{1}$ Corresponding Author: Poltekkes Kemenkes Malang Kampus 2 Lawang Jln. Yani Lawang Malang Jawa Timur, Indonesia; Email: marsaidsaid411@gmail.com
} 


\section{PENDAHULUAN}

Kecelakaan dan kondisi-kondisi kegawatan dapat terjadi dimana saja, kapan saja dan menyerang siapa saja. Kesalahan atau keterlambatan dalam penanganan awal dapat mengakibatkan semakin memburuknya kondisi korban yang bisa mengakibatkan kecacatan atau komplikasi lainnya. Tidak jarang bahkan sampai berujung pada kematian (Heller, Jacob H, 2015). Saat ini insiden pasien henti jantung dan henti napas sangat meningkat kejadiannya dan memerlukan bantuan segera dalam penyelamatannya. Kejadian henti jantung dan henti napas merupakan penyebab kematian terbanyak, $70 \%$ henti jantung terjadi diluar rumah sakit, $50 \%$ tidak berhasil diselamatkan, 10,8 \% bisa terselamatkan diluar rumah sakit dan 25,5\% bisa terselamatkan didalam rumah sakit. Sedangkan untuk kecelakaan lalu lintas, insidennya meningkat $6,72 \%$ dari kasus sebelumnya. Dikatakan juga bahwa rata-rata 84 orang meninggal setiap harinya karena kecelakaan (American Heart Association, 2015).

Kegawatdaruratan secara umum dapat diartikan sebagai suatu keadaan yang dinilai sebagai ketergantungan seseorang dalam menerima tindakan medis atau evaluasi tindakan dengan segera (Ibrahim et al, 2016). Tetapi adakalanya tindakan medis ini tidak bisa didapatkan korban dengan segera. Ada beberapa hal yang mempengaruhinya, salah satunya adalah keterjangkauan korban dari fasilitas pelayanan kesehatan yang ada. Pada kondisi ini, kecepatan dan ketepatan dalam mendapatkan pertolongan pertama merupakan kunci keberhasilan korban melalui fase kritisnya. Sehingga angka kematian dan kecacatan dapat diturunkan (Olumide et al, 2015).

Sistem Pelayanan Gawat Darurat Terpadu (SPGDT) menjadi solusi terpilih terbaik untuk memberi bantuan bagi seseorang dengan kriteria "gawat darurat". Pusponegoro (2005) menyatakan bahwa suatu sistem yang baik akan tercermin dari waktu tanggap (Respon Time) sesaat setelah cedera terjadi. Keberhasilan pertolongan terhadap penderita gawat darurat itu tergantung kepada tiga hal yaitu kecepatan ditemukannya penderita, kecepatan meminta bantuan pertolongan dan kecepatan dan ketepatan bantuan yang diberikan. Melihat ketiga faktor tersebut dapat dimengerti bahwa pertolongan pertama di tempat kejadian (on the spot) sebaiknya dilakukan oleh penolong yang memahami prinsip resusitasi dan stabilisasi, ekstrikasi dan evakuasi, serta cara transportasi penderita dengan benar (Ibrahim et al, 2016).

Pertolongan pertama (first aid) adalah memberikan pertolongan secara cepat dan bersifat sementara waktu yang diberikan pada seseorang yang menderita luka atau terserang penyakit mendadak yang memerlukan penanganan medis dasar, sebelum korban mendapatkan penanganan medis (Altintas et al, 2015). Pertolongan pertama bertujuan untuk menyelamatkan jiwa korban, mencegah kecacatan dan memberikan kenyamanan yang amenunjang proses penyembuhan. Untuk itu, pertolongan pertama harus dilakukan secara cepat dan tepat dengan menggunakan sarana dan prasarana yang ada di tempat kejadian.

Faktanya kemampuan memberikan pertolongan pertama secara cepat dan sekaligus tepat ini belum banyak dimiliki oleh masyarakat. Padahal kelompok masyarakat inilah yang nantinya akan banyak berperan sebagai first responder pada kondisi kegawatan. Beberapa contoh kejadian, korban pada kasus kecelakaan lalu lintas, tindakan pertama masyarakat adalah langsung memindahkan korban ke tepi jalan 
bahkan hanya dengan 2 orang penolong dan memberi mereka minum. Pada kasus kejang, beberapa kelompok meyakini bahwa korban harus disiram air. Pada luka tusuk, masyarakat pada umumnya akan secara otomatis mencabut benda penusuk yang menempel di tubuh korban. Masyarakat tidak menyadari bahwa tindakan yang dilakukan dengan niat baik ini malah akan semakin beresiko memperberat kondisi korban.

Kedudukan tenaga PMR di sekolah yang terlatih di tahap prahospital di dalam SPGDT memiliki posisi sangat strategis. Kondisi penderita yang membutuhkan jalan napas yang bersih, ventilasi paru adequat, sirkulasi darah yang baik dan terhindar dari perdarahan lanjut serta terlindungi dari kecacatan menjadi poin penting bahwa seorang penolong pertama harus mempunyai dasar keilmuan yang memadai tentang keterampilan Penanggulangan Penderita Gawat Darurat (PPGD).

SMP Bayt Al-Hikmah Pasuruan merupakan SMP Swasta yang diintegrasikan dengan pondok pesantren. Di sekolah tersebut telah terdapat UKS dan didalamnya telah terbentuk palang merah remaja (PMR). Namun anggota yang ada di PMR tersebut belum mempunyai pengetahuan dan ketrampilan dalam penanganan kegawatdaruratan. Melalui kegiatan pelatihan pertolongan kegawatdaruratan dasar diharapkan dapat meningkatkan pengetahuan dan ketrampilan kegawatdaruratan dasar pada anggota PMR di SMP Bayt Al-Hikmah Pasuruan. Untuk itu dirasa perlu meningkatkan ketrampilan masyarakat terutama kelompok remaja dalam pemberian pertolongan pertama. Remaja sebagai generasi pembaharu diharapkan bisa menjalankan peran sebagai first responder dengan baik. Sebagai langkah awal, Tim Pengabmas memfokuskan pada remaja yang tergabung di tim PMR yang ada di sekolahnya. Tujuan pelatihan pertolongan kegawatdaruratan dasar ini adalah diharapkan anggota PMR mampu melakukan pertolongan pertama kepada masyarakat disekitarnya yang mengalami kecelakaan atau kondisi kegawatan.

\section{METODE}

Kegiatan pengabdian masyarakat terdiri atas pelatihan secara teori di kelas dan pelatihan skill dengan jumlah total peserta sebanyak 50 orang. Adapun metode pelaksanaannya dijabarkan seperti dibawah ini:

\section{Tahap 1. Persiapan}

Melakukan survey awal di SMP Bayt Al-Hikmah Kota Pasuruan, melakukan koordinasi dengan panitia pengabdian masyarakat kampus, mengajukan surat permohonan pengabdian masyarakat kepada Jurusan Keperawatan Malang, mengajukan proposal kegiatan ke lahan dan melakukan koordinasi dengan Bagian Kesiswaan SMP Bayt Al-Hikmah Kota Pasuruan.

\section{Tahap 2. Pelaksanaan}

a. Ceramah.

Ceramah merupakan cara penyampaian materi yang terus menerus berusaha menjaga terjalinnya suatu komunikasi interaktif antara peserta dan pengajar. Kuliah 
interaktif ditujukan untuk meningkatkan pengetahuan peserta memahami penatalaksanaan First Aid.

b. Praktikum

Praktikum diberikan agar peserta memahami dan dapat melakukan dengan benar tindakan penanganan Pertolongan pertama kegawatan dasar berupa penilaian pasien dan tanda-tanda vital, pembalutan, imobilisasi dan pembidaian serta mengangkat dan memindahkan pasien, sesuai dengan materi yang telah diberikan.

c. Demonstrasi

Demonstrasi dilakukan saat pelatihan skill berlangsung dan disesuaikan dengan jadual putaran skill. Beberapa contoh demonstrasi yang dilakukan antara lain : demonstrasi cara pembalutan dan pembidaian pada korban dengan cidera jaringan lunak. demonstrasi evakuasi penderitra.

\section{Tahap 3. Evaluasi}

Evaluasi dilaksanakan pada awal dan akhir pelatihan dalam bentuk ujian tulis yaitu pre test dan post test. Laporan dilakukan secara dua tahap. Tahap pertama adalah laporan kemajuan pertama dan yang kedua adalah laporan tahap kedua secara keseluruhan kegiatan pengabdian masyarakat yang terdiri dari pelaksanaan kegiatan, pertanggungjawaban anggaran keungan dan evaluasi kegiatan.

\section{HASIL DAN PEMBAHASAN}

Kegiatan pengabdian Masyarakat yang dilakukan pada tanggal 29 dan 31 Agustus 2019 di SMP Bayt Al-Hikmah Kota Pasuruan diawali dengan kegiatan pembukaan oleh Ketua Tim Pengabmas dan Bagian Kesiswaan SMP Bayt Al-Hikmah Kota Pasuruan dengan diikuti oleh 50 siswa PMR SMP Bayt Al-Hikmah Kota Pasuruan. Acara dilanjutkan dengan pelaksanaan Pre Test untuk mengukur kemampuan peserta.

\section{Karakteristik Peserta Pelatihan}

Tabel 1 Distribusi Frekuensi Responden Peserta Pengabmas berdasarkan Jenis Kelamin di SMP Bayt Al-Hikmah Kota Pasuruan

\begin{tabular}{rlcc}
\hline No. & Jenis Kelamin & Frekuensi & Prosentase (\%) \\
\hline 1. & Laki - laki & 25 & 50 \\
2. & Wanita & 25 & 50 \\
\hline & Jumlah & 50 & 100 \\
\hline
\end{tabular}

Berdasarkan Tabel 1 menunjukkan bahwa, jenis kelamin peserta pelatihan antara wanita dan pria adalah sama yaitu masing-masing sebanyak 25 orang (50\%).

\section{Hasil Kemampuan Pertolongan Pertama Pada Kegawatan Dasar Anggota PMR Sebelum dan Setelah Pelatihan Kegawatan dasar}

Berdasarkan Tabel 2 dan diagram 1 menunjukkan bahwa terjadi peningkatan yang signifikan terhadap kemampuan anggota PMR, hal ini ditunjukkan dari hasil pre test nilai terendahnya adalah 36, nilai tertinggi 60 dan nilai rata-ratanya 55,4. Sedangkan 
hasil post-test didapatkan nilai terendah 75 dan nilai tertingginya 90 , dengan nilai ratarata 85,6 .

Tabel 2 Distribusi Kemampuan Anggota PMR Sebelum dan Setelah Pelatihan Kegawatan dasar

\begin{tabular}{lccccccccc}
\hline & \multicolumn{3}{c}{ Sebelum Pelatihan } & \multicolumn{4}{c}{ Setelah Pelatihan } \\
\hline $\begin{array}{l}\text { Kemampuan } \\
\begin{array}{l}\text { Pertolongan } \\
\text { Kegawatan Dasar }\end{array}\end{array}$ & \begin{tabular}{c} 
Jumlah \\
\cline { 2 - 9 }
\end{tabular} & Min & Max & Mean & $\begin{array}{c}\text { Jumlah } \\
\text { (f) }\end{array}$ & Min & Max & Mean \\
\hline
\end{tabular}

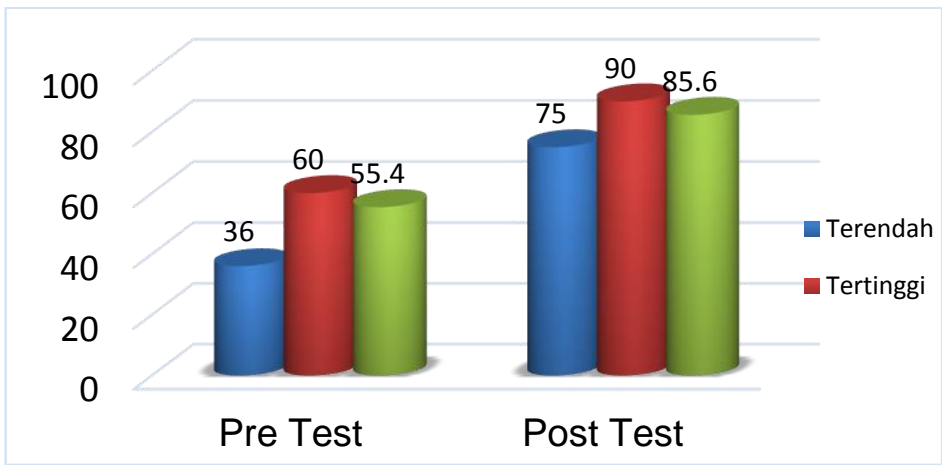

Diagram 1 Kemampuan Anggota PMR Sebelum dan Setelah Pelatihan Pertolongan Pertama Pada Kegawatan Dasar

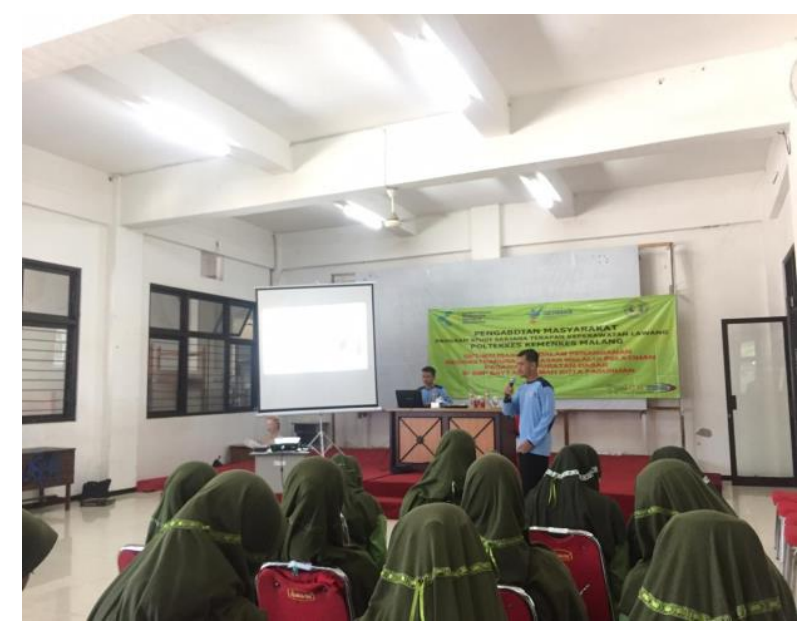

Gambar 1. Ceramah Materi Pelatihan Pertolongan Pertama Pada Kegawatan Dasar

Selama kegiatan pelatihan para anggota PMR tampak terlihat sangat intens. Banyak pertanyaan muncul terutama pada saat pemeberian materi dan praktek. Hasil pengamatan menunjukkan bahwa para anggota PMR masih belum mengetahui secara terstruktur terkait dengan pertolongan pertama pada kecelakaan, apalagi pada saat penyampaian materin patah tulang dan penanganannya, luka gigitan ular, cedera pada kepala dan pada saat praktek pembidaian. Sejalan dengan analisis permasalahan yang ditemukan dilapangan antara lain: kurangnya pemahaman dan ketrampilan yang dimiliki oleh para anggota PMR tentang Pertolongan Pertama Pada Kegawatan Dasar, 
kurangnya pemahaman dan ketrampilan yang dimiliki oleh para anggota PMR, kurangnya kuantitas pelatihan Pertolongan Pertama Pada Kegawatan Dasar bagi para anggota PMR.

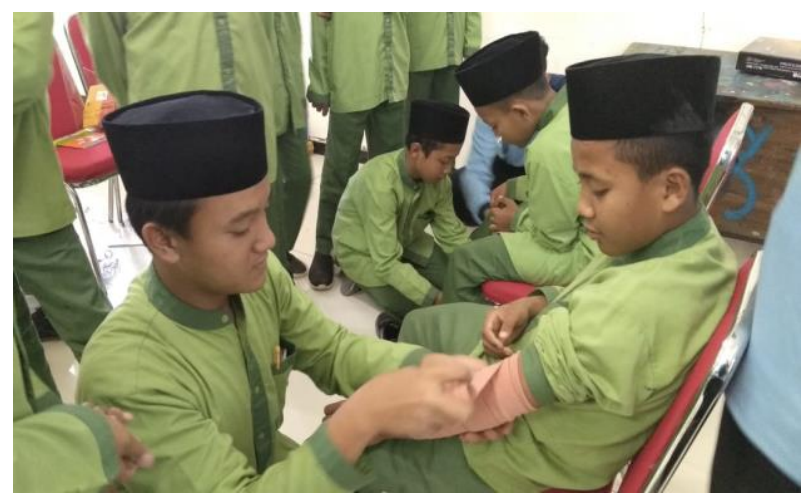

Gambar 2. Praktikum Pemasangan bidai pada ekstremitas atas

Selama kegiatan pelatihan, permasalahan tersebut sudah bisa diselesaikan dengan baik oleh nara sumber dan tim. Salah satu ketrampilan yang harus dimiliki oleh anggota PMR tentang Pertolongan Pertama Pada Kegawatan Dasar adalah terkait materi patah tulang dan praktek melakukan pembidaian. Secara umum, proses pelaksanaan kegiatan pengabdian kepada masyarakat ini berjalan lancar dan tidak mengalami kendala yang berarti. Untuk mengetahui efektifitas kegiatan pengabdian ini, pada kegiatan pengabdian selanjutnya perlu dilakukan refreshing terkait materi yang pernah diajarkan dan melakukan evaluasi hingga pada ketrampilan anggota PMR melakukan pertolongan pertama pada kondisi kegawatan.

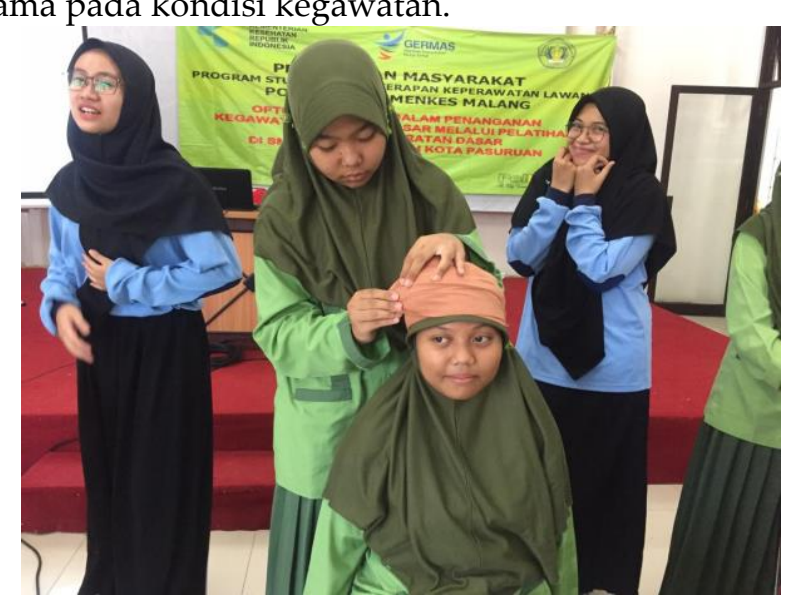

Gambar 3. Praktikum Pemasangan balutan pada kepala

Pelatihan Pertolongan Pertama kegawatdaruratan dasar dapat diberikan kepada setiap orang, baik petugas kesehatan maupun orang awam khusus (siswa anggota PMR) dalam menanggulangi suatu keadaan yang mengancam nyawa (gawat) dengan situasi yang terbatas dan segera (darurat). Pertolongan pertama merupakan tindakan awal yang harus segera diberikan pada korban yang mengalami masalah kegawatdaruratan akibat kecelakaan atau insiden gawat darurat ataupun oleh penyakit mendadak sebelum datangnya ambulans, dokter atau petugas terkait lainnya (Zhou et al,2016). 
Masalah kegawatdaruratan dapat menimpa siapa saja, dimana saja dan kapan saja, insiden gawat darurat kadang tak dapat terelakkan. Keadaan gawat darurat dapat disebabkan oleh kecelakaan, penyakit, kimiawi, kebakaran ataupun faktor kesengajaan (Hsiao et al, 2017).

Persoalan Pertolongan Pertama Dawat Darurat seringkali masih dianggap oleh kebanyakan orang adalah sebagai tanggung jawab para petugas kesehatan semata. Hal ini dapat dimaklumi karena mungkin informasi lengkap mengenai pemberian pertolongan pertama gawat darurat belum diperoleh. Padahal kenyataan di lapangan peran serta ataupun keterlibatan masyarakat dapat sangat berpengaruh, mulai dari mengurangi rasa nyeri, meringankan penderitaan, sampai menyelamatkan nyawa seseorang.

Angka kematian atau kecacatan akibat kecelakaan maupun insiden gawat darurat lainnya tiap tahun cukup tinggi. Hal yang ditunjuk sebagai penyebabnya antara lain ialah keterlambatan penanganan korban maupun kesalahan penanganan pertama oleh orang-orang yang pada saat kejadian berada di sekitar korban. Pemberian pertolongan pertama kepada korban adalah suatu hal yang sangat penting dalam upaya penyelamatan hidup serta pencegahan kecacatan ( $\mathrm{Li}$ et al, 2012). Untuk dapat melakukan pertolongan pertama memiliki arti sama dengan menguasai ketrampilan yang berdasarkan pengetahuan, latihan dan pengalaman. Disamping itu upaya pertolongan pertama pada kegawatan dan kedaruratan bukan hanya masalah ketrampilan melakukan bantuan hidup dasar. Terkadang upaya pertolongan pertama harus berhadapan dengan kondisi "Live Saving" atau keadaan yang mengancam nyawa bagi korban.

\section{SIMPULAN}

Pelatihan pertolongan pertama kegawatdaruratan dasar yang telah diselenggarakan mampu meningkatkan pengetahuan siswa siswi anggota PMR tentang dasar-dasar memberikan pertolongan pada kegawatdaruratan di sekolah, penilaian korban, pembalutan dan pembidaian, bantuan sumbatan jalan napas, perdarahan dan cidera dengan rata rata skor pengetahuan 55,4 menjadi 85,6 .

Peserta menyatakan senang mendapatkan pelatihan tentang pertolongan pertama kegawatan dasar dan menyatakan mau dan tertarik untuk mempelajari pertolongan pertama kegawatdaruratan dasar. Aspek psikomotor/tindakan Peserta mampu melakukan pertolongan pertama kegawatan dasar pada kasus patah tulang dengan pemasangan balut bidai, kasus perdarahan dengan tindakan bebat tekan, serta penanganan sumbatan benda asing dengan benar.

Kegiatan Pelatihan Pertolongan pertama kegawatan dasar ini sebaiknya dilakukan secara rutin terutama untuk penyegaran/refreshing, pembaruan/up dating dan pengembangan serta pembinaan anggota PMR di sekolah-sekolah dan masyarakat. Sekolah melalui pembina UKS perlu mengadakan perekrutan anggota PMR yang baru setiap tahun. Tim pengabdian masyarakat perlu memberikan pendampingan dan evaluasi secara berkala terkait pemanfaatan UKS yang siap dan tanggap darurat. 


\section{REFERENSI}

Altintas, K. H., Aslan, D., Yildiz, A. N., Subasi, N., Elçin, M., Odabasi, O., ... \& Sayek, I. (2005). The evaluation of first aid and basic life support training for the first year university students. The Tohoku journal of experimental medicine, 205(2), 157-169. http://dx.doi.org/10.1620/tjem.205.157

American Heart Association. (2015). Adult basic life support and cardiopulmonary resuscitation. Retrieved January 5, 2019 from https://www.ahajournals.org/doi/full/10.1161/cir.0000000000000259

Başer, M., Çoban, S., Taşci, S., Sungur, G., \& Bayat, M. (2007). Evaluating first-aid knowledge and attitudes of a sample of Turkish primary school teachers. Journal of Emergency Nursing, 33(5), 428-432. http://dx.doi.org/10.1016/j.jen.2006.11.003

Engeland, A., Røysamb, E., Smedslund, G., \& Søgaard, A. J. (2002). Effects of first-aid training in junior high schools. Injury Control and Safety Promotion, 9(2), 99-106. http://dx.doi.org/10.1076/icsp.9.2.99.8702

Heller, Jacob H. (2015). CPR-Infant. Retrieved March 25, 2019 from https://medlineplus.gov/ency/article/000011.htm

Hsiao, M., Tsai, B., Uk, P., Jo, H., Gomez, M., Gollogly, J. G., \& Beveridge, M. (2007). "What do kids know": A survey of 420 Grade 5 students in Cambodia on their knowledge of burn prevention and first-aid treatment. Burns, 33(3), 347-351. http://dx.doi.org/10.1016/j.burns.2006.08.002

Ibrahim, A., Sam-Agudu, N., Omaye, U., Ushie, B., Olumide, A., \& Omotade, O. (2016). 933 Impact of first aid training on the first aid knowledge and skills capacity of primary school teachers in Ibadan, Nigeria. Injury Prevention, 22, 332

Li, F., Jiang, F., Jin, X., Qiu, Y., \& Shen, X. (2012). Pediatric first aid knowledge and attitudes among staff in the preschools of Shanghai, China. BMC Pediatrics, 12(1), 18. https://doi.org/10.1186/1471-2431-12-121

Olumide, A. O., Asuzu, M. C., \& Kale, O. O. (2015). Effect of first aid education on first aid knowledge and skills of commercial drivers in South West Nigeria. Prehospital and disaster medicine, 30(6), 579-585. https://doi.org/10.1017/S1049023X15005282.

Pusponegoro. (2005). Perspektif keperawatan gawat darurat. Jakarta: EGC.

Zhou, M. R., Zhou, S. X., Zhi-Hua, X., \& Qiong-Yue, S. (2016). 934 Interventions to reduce injuries among students in primary and secondary schools in Xining City. Injury Prevention, 22, 397.

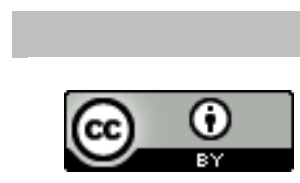

\section{Copyright and License}

This is an open access article distributed under the terms of the Creative Commons Attribution 4.0 International License, which permits unrestricted use, distribution, and reproduction in any medium, provided the original work is properly cited. (C) 2020 Marsaid. 